\title{
CONVENIENT SYNTHESIS OF SUBSTITUTED 2-PHENYL QUINIXALINE FROM $\alpha$-TOSYL KETONES AND ARYL 1,2- DIAMINES CATALYSED BY L-PROLINE
}

\author{
Shankar Poshatti Hangirgekar \\ Department of Chemistry, Shivaji University, Kolhapur-461004, Maharastra, India \\ E-mail: hangirgekarshankar@gmail.com
}

\begin{abstract}
In the present methodology, we have reported the synthesis of substituted phenyl quinoxaline derivatives by using 1,2-phenylenediamines and $\alpha$ - tosyl ketones in presence of L-Proline as a catalyst and dichloromethane as solvent. This methodology is useful for the synthesis of quinoxaline derivatives with high yields..
\end{abstract}

Keywords: $\alpha$-tosyl ketone, aryl 1,2 diamine, L-Proline, dichloromethane

(C) RASĀYAN. All rights reserved

\section{INTRODUCTION}

Quinoxaline is a mostly used heterocyclic compound, which has been subjected to a large variety of structural modifications in order to synthesize derivatives with different biological and medicinal properties $^{1-5}$ such as antidepressant, ${ }^{6}$ anticancer, ${ }^{7}$ antiinflammatory, ${ }^{8,9}$ antimicrobial ${ }^{10,11}$ and antiviral ${ }^{12,13}$. Some of the important reports on quinoxaline derivatives such as microwave-assisted synthesis of quinoxalines derivatives from $o$-phenylenediamine, 1, 2- dicarbonyl compounds and iodine as catalyst ${ }^{14}$. Kumar A. and co-workers demonstrated synthesis of quinoxaline using glyoxal and $o$ - phenylenediamine derivatives in acetonitrile ${ }^{15}$ Mohga M. Badran reported piperidine catalyzed reaction between 3-methyl quinoxaline, aromatic aldehyde and acetic anhydride for the preparation of 3-substituted styrylquinoxalin2(1H)-ones ${ }^{16}$.Thakuria H.and Das G. described the synthesis of 3-methyl quinoxaline-2-one by condensation of $o$-phenylenediamine with pyruvic acid in $\mathrm{DMF}^{17}$. Islami R. M. and Hassani Z. developed an ecofriendly synthesis of quinoxalines derivatives from o-phenylenediamine and $\alpha$-hydroxy ketones in acetic acid via two methods: microwave irradiation and simple heating ${ }^{18}$.

Ghadari R. and co-workers demonstrated synthesis of6-hydroxy-benz- quinoxaline-2, 3-dicarbonitrile from diaminomaleonitrile, 2-hydroxy-1,4-naphthoquinone in acetic acid at room temperature ${ }^{19}$.J. S. Sandhu used 1,2-diamine, 1,2-diketone, $\mathrm{RuCl}_{3} \cdot \mathrm{xH}_{2} \mathrm{O}$ and [bmim] $\mathrm{PF}_{6}$ for the synthesis of 2,3-Diphenylquinoxaline ${ }^{20}$. Another methodology for the synthesis of quinoxaline derivatives involved condensation of o-phenylenediaminediamines with $\alpha$-bromoketones, and epoxides ${ }^{21-24}$. Other notable approaches involve the employment of various nitro compounds, such as $o$-nitroaminobenzenes, $o$-halonitrobenzenes, and $\alpha$ nitroketene $N, S$-anilinoacetals ${ }^{25-27}$.

Therefore, to achieve the green synthetic method for the synthesis of highly functionalized quinoxaline derivatives herein, we developed a facile synthesis of substituted quinoxalines from $\alpha$-functionalized ketones such as alpha tosyl ketone. Our continuing interest in such ketones as intermediates and the organic reactions in aqueous media prompted us to explore the reactions of $\alpha$-tosyl ketones with benzene1,2-diamine and 2-aminophenol in basic media. As a result, we successfully achieved an environmentfriendly process for the synthesis of substituted quinoxalinesunder very mild conditions, with good yield and synthesized compounds will be evaluated for antimicrobial activity.

\section{EXPERIMENTAL}

All chemicals and reagents were of analytical grade and $\alpha$-tosyl ketones were synthesized using known procedure. Melting points were taken in open capillary tubes using super fit melting apparatus and are uncorrected.

Rasayan J. Chem., 12(1), 329-332(2019)

http://dx.doi.org/10.31788/RJC.2019.1212058

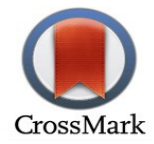


RASĀYAN J. Chem.

Vol. 12 | No. 1 |329 - 332| January - March | 2019

\section{Synthesis of Substituted2-phenylquinoxaline}

General Procedure for the Synthesis of 2-phenylquinoxaline A mixture of $\alpha$-tosyl ketones (1.0 mmol) and 1,2-diamine $(1.0 \mathrm{mmol})$ in the presence of L-proline $(10 \mathrm{mmol} \%)$ in dichloromethane $(20 \mathrm{~mL})$. The reaction mixture was stirred at room temperature for 8-9 hr. The completion of the reaction was monitored by TLC by using petroleum ether and ethyl acetate (8: 2) as an eluent. The reaction mixture was poured into crushed ice, extracted with ethyl acetate $(3 \times 25 \mathrm{~mL})$, dried and purified by crystallization from ethyl alcohol to give the corresponding products.

\section{RESULTS AND DISCUSSION}

Initially, we concentrated on the reaction of 1-(4-bromophenyl)-2-tosylethanone $(1.0 \mathrm{mmol})$ and 1,2phenylenediamine $(1.0 \mathrm{mmol})$ were dissolved in dichloromethane $(20 \mathrm{~mL})$ and L-proline $(10 \mathrm{mmol} \%)$ was added with constant stirring at room temperature and the mixture was stirred for $8 \mathrm{hr}$. TLC indicated the disappearance of the starting material. The reaction mixture was poured into crushed ice, extracted with ethylacetate $(3 \times 25 \mathrm{~mL})$ and dried over $\mathrm{Na}_{2} \mathrm{SO}_{4}$. The solvent was removed under vacuum and purified by crystallization from ethyl alcohol to give the corresponding products. The cyclization reaction proved to be suitable for $\alpha$-tosyl ketones affording the corresponding substituted quinoxaline, with good yields (Table-1). The results are shown in Table-1 demonstrate the new methodology and efficiency of the cyclization reaction. The validity of this cyclization reaction was further evaluated by performing the reactions of $\alpha$-tosyl ketones with 2 -aminophenol with the aim of synthesizing the oxygen-containing heterocycles.

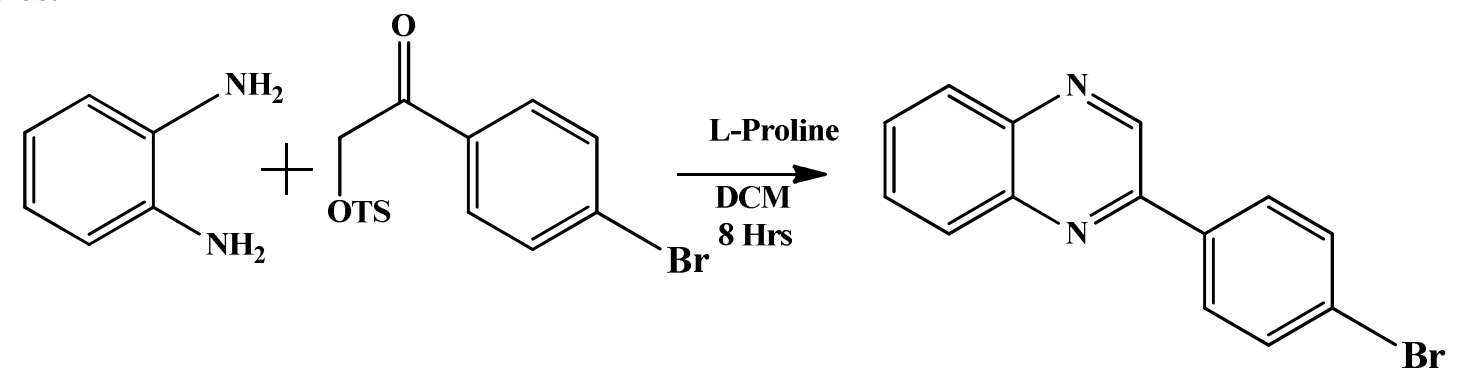

Scheme-1: Synthesis of Quinoxaline Derivatives

Table -1: Synthesis of Quinoxaline Derivatives using $\alpha$-Tosyloxy Ketone and 1,2-Diamine

Entry


RASĀYAN J. Chem.

Vol. 12 | No. 1 |329 - 332| January - March | 2019

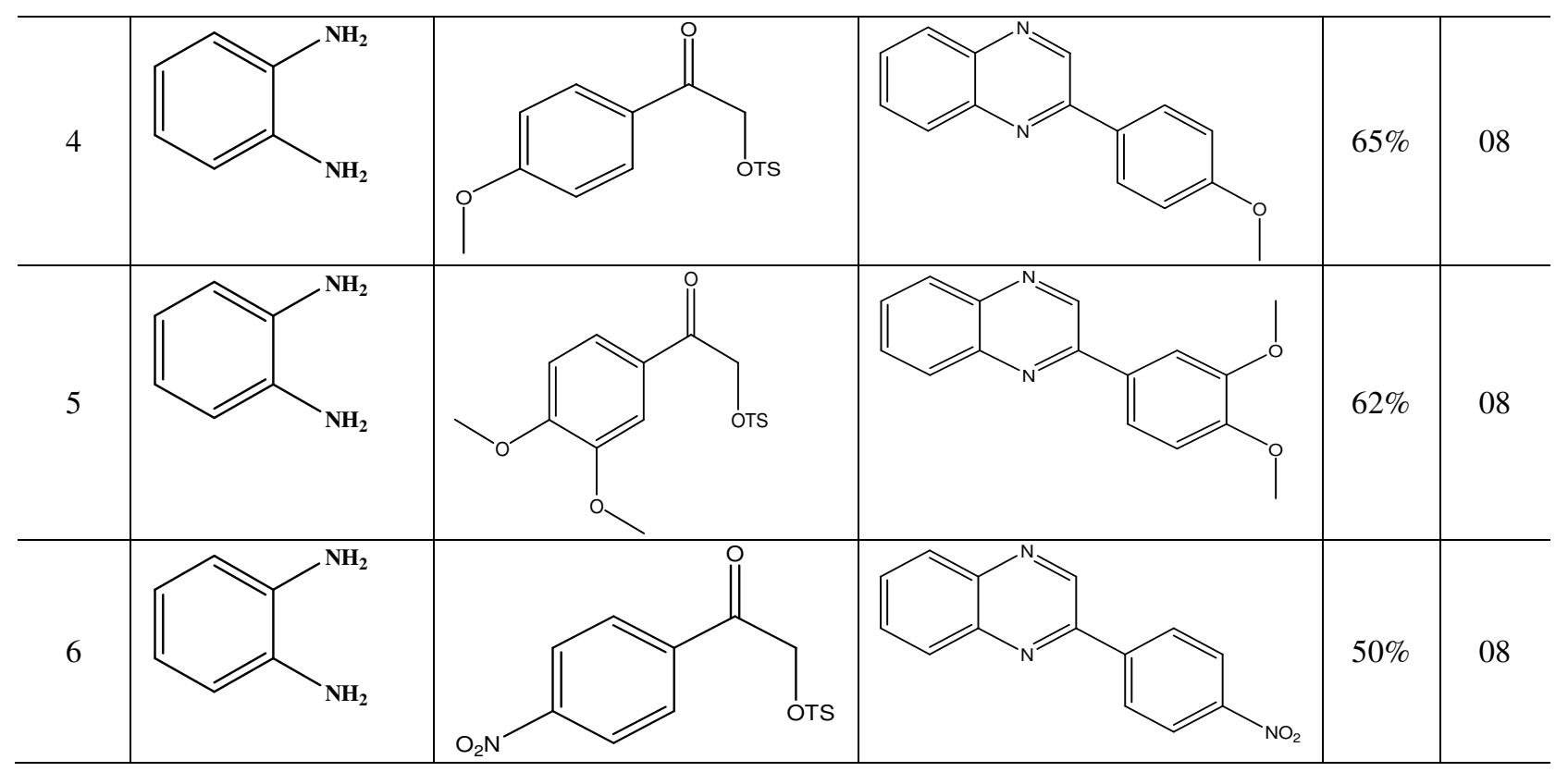

CONCLUSION

In conclusion, a superficial and suitable methodology developed for the synthesis of substituted quinoxalines from the reaction of $\alpha$-tosyl ketones with O-phenyl diamine, using catalyst L-Proline and dichloromethane, as a solvent with moderate-to-good yields. The methodology is associated with the ecofriendly process, very mild conditions, good yield, particularly in relation to the recent environmental concerns.

\section{REFERENCES}

1. T. Eicher and S. Hauptmann, The Chemistry of Heterocycles, Thieme, New York, p.417 (1995).

2. A. E. Porter, A. R. Katritzky and C. W. Rees, (Eds.), Comprehensive Heterocyclic Chemistry, Pergamon Press, Oxford, p. 157 (1984).

3. N. Sato, A. R.Katritzky, C. W. Rees and E. F. V. Scriven, (Eds.), Comprehensive Heterocyclic ChemistryII, Pergamon Press, Oxford, p.233 (1996).

4. L. E. Seitz, W. J. Suling and R. C. Reynolds, J. Med. Chem., 45, 5604(2002), DOI: $10.1021 / \mathrm{jm} 020310 \mathrm{n}$

5. A. Gazit, H. App and G. McMahon, et al., J. Med. Chem., 39,2170(1996), DOI: 10.1021/jm950727b

6. R. Sarges, H. R. Howard, R. G. Browne, L. A.lebel, P. A. Sey- mour and B. K. Koe, J. Med. Chem.,33, 2240(1990), DOI: 10.1021/jm00170a031

7. H. W. Yoo M.E. Suh and S.W. Park, J. Med. Chem.,41(1998), DOI: 10.1021/jm970695n

8. S. B. Kadin, (Pfizer Inc.) Ger. Offen. 1974, 2,357,186; Chem. Abstr. 1974, 81, 37574.

9. C. V. Reddy Sastry, K. S. Rao, V. S. H. Krishnan, K.Rastogi, M. L. Jain and G. K. A. S. S. Narayan, Indian J. Chem., 29B, 396(1990)

10. I. M. AAwad, Indian J. Chem., 30B, 89(1991)

11. Y. Kurasawa and H. S. Kim, J. Heterocycl. Chem., 35, 1101(1998), DOI: 10.1002/jhet.5570350509

12. Z. Zhu, S.Saluja, J. C. ,Drach and L. B. Townsend, J. Chin. Chem. Soc., 45, 465(1998), DOI: $10.1002 /$ jccs.199800071

13. G. Campiani, F. Aiello, M. Fabbrini, E. Morelli, A. Ramunno, S. Armaroli, V. Nacci, A. Garofalo, G. Greco, E. Novellino, G. Maga, S. Spadari, A. Bergamini, Ventura, L. B. Bongiovanni, M. Capozzi, F. Bolacchi, S. Marini, M. Coletta, G. Guiso and S. Caccia, J. Med. Chem., 44, 305(2001), DOI: $10.1021 / \mathrm{jm} 0010365$

14. D. Bandyopadhyay, S. Mukherjee, R. R. Rodriguez and B. K. Banik, Molecules, 15, 4207 (2010), DOI: $10.3390 /$ molecules 15064207 
RASĀYAN J. Chem.

Vol. 12 | No. 1 |329 - 332| January - March | 2019

15. A. Kumar, S. Kumar, A. Saxena and S. Mozumdar, Catal. Commun., 9,778(2008), DOI: 10.1016/j.catcom.2007.08.021

16. M. B. Mohga, A. M. Ashraf, M. R. Hanan and A. El. Afaf, Journal of the Chinese Chemical Society, 54, 469(2007), DOI: $10.1002 /$ jccs.200700066

17. H. Thakuria and G. Das, J. Chem. Sci.,118, 425(2006).

18. R. M. Islami and Z. Hassani, Arkivoc, xv, 280(2008), DOI: 10.3998/ark.5550190.0009.f24

19. R. Ghadari, F. Hajishaabanha, M. Aghaei, A. Shaabani, N. S. Weng, Mol Divers, 16, 453(2012), DOI: $10.1007 / \mathrm{s} 11030-012$

20. Suresh, R. S. Bhatti and J.S. Sandhu, Rasayan J. Chemistry, 5, 432 (2012)

21. S. A. Raw, C. D. Wilfred and R. J. K. Taylor, Chem. Commun., 18, 2286(2003), DOI:10.1039/B307177B

22. S. Y. Kim, K. H. Park and Y. K. Chung, Chem. Commun.,10, 1321(2005), DOI: 10.1039/B417556E

23. S. Antoniottia and E. Dunach, Tetrahedron Lett., 43, 3971(2002), DOI:10.1016/S00404039(02)00715-3

24. E. C. Taylor, C. A. Maryanoff and J. S. Skotnicki, J. Org. Chem., 45, 2512 (1980), DOI: $10.1021 /$ jo01300a053

25. Z. Wu and N. J. Ede, Tetrahedron Lett., 42, 8115 (2001), DOI: 10.1016/S0040-4039(01)01733-6

26. G. S. M. Sundaram, B. Singh and C. Venkatesh, et al., J. Org. Chem., 72, 5020 (2007), DOI: $10.1021 /$ jo070590k

27. C. Venkatesh, B. Singh and P. K.Mahata, et al., Org. Lett., 7, 2169 (2005), DOI: 10.1021/o10505095

[RJC-2058/2018] 